\title{
A SUSTENTABILIDADE COMO FERRAMENTA ESTRATÉGICA EMPRESARIAL: GOVERNANÇA CORPORATIVA E APLICAÇÃO DO TRIPLE BOTTOM LINE NA MASISA
}

\author{
SUSTAINABILITY AS BUSINESS STRATEGIC: \\ THE CORPORATE GOVERNANCE AND APPLICATION \\ OF THE TRIPLE BOTTOM LINE IN MASISA
}

Recebido: $22 / 05 / 2013$

Aceite: $02 / 07 / 2013$

Lira Luz Lazaro Benites ${ }^{1}$

Edison Fernandes Polo ${ }^{2}$

\section{RESUMO}

A ideia de sustentabilidade na empresa indica que, para alcançar um bom desempenho econômico, as empresas devem adotar uma estratégia que contemple o conceito triple bottom line, segundo o qual, as empresas devem prestar contas de sua performance nas áreas econômica, ambiental e social. $\mathrm{O}$ presente trabalho tem por objetivo descrever os benefícios de colocar a sustentabilidade no cerne da Governança Corporativa, como estratégia empresarial que gera valor a partir da busca de melhores resultados sociais e ambientais. Menciona-se o exemplo da empresa Masisa para analisar a implementação Triple Bottom Line e a Governança Corporativa em dois países que a empresa atua, Brasil e Chile.

Palavras-chave: Governança Corporativa; Sustentabilidade; Responsabilidade ambiental; Responsabilidade Social.

1 Possui graduação em Direito e Ciencias Sociais pela Universidad Privada Los Angeles de Chimbote e mestrado em Sociedade, Economia e Estado pelo programa de pós-graduação em Integração da América Latina pela Universidade de São Paulo - USP. Atualmente é doutoranda pelo programa de pós-graduação em Integração da América Latina pela Universidade de São Paulo - USP. São Paulo, São Paulo, Brasil. E-mail: Ibenites@usp.br.

2 Possui graduação e mestrado em Administração pela Fundação Getúlio Vargas - FGV, doutorado em Administração pela Universidade de São Paulo - USP e livre-docência em marketing pela Universidade de São Paulo - USP. Atualmente é professor Associado do DA/FEA/USP, pesquisador, palestrante e consultor de empresa. São Paulo, São Paulo, Brasil. E-mail: Polo@usp.br. 


\section{ABSTRACT}

The idea of sustainability in a company indicates that to achieve a good economic performance, companies should adopt a strategy that includes the triple bottom line concept, according to which the companies should be accountable for their performance in the economic, environmental and social areas. This paper aims to describe the benefit to put sustainability at the heart of the corporate governance as a business strategy that will generates value from the search for better social and environmental outcomes. We mention the example of the Masisa Company to analyze the implementation of the Triple Bottom Line and Corporate Governance in both countries where it operates, Brazil and Chile.

Keywords: Corporate Governance; Sustainability; Triple Bottom Line; Environmental Responsibility; Social Responsibility.

\section{INTRODUÇÃO}

Segundo Morelba (2007), no contexto pós-Enron³, as empresas precisam estabelecer uma distinção entre a perspectiva financeira da governança empresarial, caracterizada pela visão reduzida e orientada aos shareholders, e a perspectiva dos acionistas, uma visão estratégica, orientada aos stakeholders (as partes interessadas), que seriam seus fornecedores, consumidores, o governo, os clientes, seus trabalhadores e a sociedade. $O$ grande diferencial já não é mais a qualidade, mas sim a postura ética e o comprometimento da empresa com seus acionistas, com a comunidade onde atua, com o meio ambiente e com a sociedade. A estabilidade da empresa, sua imagem perante o público e sua capacidade de satisfazer os seus clientes passam a ocupar papel de destaque.

Tricker (1984 apud Coimbra, 2011) considera que o propósito da governança não está relacionado somente com a operação do negócio em si, mas também com fornecer o direcionamento geral do empreendimento, com a supervisão e o controle das ações dos gestores, e com a satisfação de expectativas legítimas quanto à prestação de contas e à regulação de interesses que vão além dos limites das empresas.

Segundo Alves (2001), o papel da empresa na sociedade não se restringe meramente à produção de bens ou à prestação de serviços em condições eficientes, assim como não se limita à maximização do lucro para os acionistas, porém consiste, antes, na geração de riqueza em um sentido mais amplo. A geração de riqueza pela empresa, para Alves (2001), pode se estender além da maximização do lucro, em benefício para os acionistas ou credores, da geração e em manutenção de empregos e do desenvolvimento de infraestrutura de pesquisa, desenvolvimento e comunicações. Ela passa a incorporar, também, a preservação dos recursos naturais não renováveis, a promoção de direitos fundamentais do trabalhador e a proteção dos interesses do consumidor.

A conexão entre governança corporativa e sustentabilidade fica mais evidente quando se observa os quatro princípios que norteiam as boas práticas de governança: transparência, prestação de contas, equidade, e responsabilidade corporativa (IBGC, 2009). Apenas através de boas práticas de governança corporativa é que uma companhia consegue ter credibilidade, atrair capital e se diferenciar no mercado (FERREIRA, 2004).

O período em que o progresso econômico era associado com o aumento exponencial do consumo de recursos, energia, de produção de bens e, até mesmo, do volume de resíduos gerados, é hoje questão controvertida (DONAIRE, 1994). Os problemas ambientais que causam danos globais e irreparáveis têm atraído o interesse da sociedade, das instituições públicas e das empresas. E, como bem menciona Sachs (2000, p. 48), "a opinião pública tornou-se cada vez

${ }^{3}$ Entre os anos 2000 e 2002, a implosão das corporações transnacionais emblemáticas e aparentemente sólidas como a Enrom, WorldCom, Auditora Andersen, Tyco, Xerox e Parmalat, entre outros, cujos diretivos foram acusados de fraude financeiros, provocou um escândalo no mundo corporativo e um crise de confiança dos investidores. Na "era pós-Enron" a reputação de empresas, além de estar relacionada com seu comportamento ético ficou obrigada a ser social e ambientalmente responsável. 
mais consciente, tanto da limitação do capital da natureza, quanto dos perigos decorrentes das agressões ao meio ambiente usado como depósito".

$\mathrm{Na}$ atualidade, os consumidores estão valorizando mais as questões ambientais, e as empresas estão compreendendo que promover a preservação do meio ambiente não é apenas uma questão de cumprimento das obrigações com os órgãos ambientais, a questão ambiental no mundo empresarial está se tornando um fator de sobrevivência organizacional e de competitividade da empresa. Quando se trata de estratégias pró-ativas, o meio ambiente é encarado como elemento de competitividade extracustos (PRAHALAD; RANGASWAMI, 2009).

Dentre os principais fatores condicionantes da necessidade de engajamento das empresas em relação à nova economia, destacam-se a continuidade de sua própria existência no mercado nacional e internacional, a obtenção de vantagem competitiva frente a seus concorrentes, e a melhoria de sua imagem, os quais podem ser alcançados se a empresa atuar como uma organização que respeita o meio ambiente. Assim, as empresas precisam expandir seu pensamento estratégico seja para a conquista de uma boa imagem corporativa, seja pela própria sobrevivência (CNI, 2011).

O modelo de cidadania corporativa de Mcintosh et.al (2001) diz que as empresas estão incluindo suas preocupações sociais e ambientais no centro de suas estratégias corporativas. A identificação dessas estratégias corporativas pode auxiliar a empresa a alcançar uma performance superior e uma vantagem competitiva (HILL; JONES, 2004) e, ainda, um desenvolvimento econômico e a gestão ambiental com destaque ao fator de competitividade (PORTER; LINDE, 1995). Assim, as empresas buscam adotar novas práticas ambientais, produzir produtos ambientalmente corretos, usar processos de produção que não agridam o meio ambiente; bem como, novos instrumentos gerenciais e certificações e selos que demonstrem seu interesse ambiental (ETHOS, 2005).

Elkington e Zollinger (2004 apud COIMBRA, 2011) ressaltam que governança corporativa, responsabilidade social empresarial e sustentabilidade são temas intrinsecamente relacionados, na medida em que qualquer negócio enfrenta, cada vez mais, um número crescente de riscos não financeiros. A introdução do conceito triple bottom line numa empresa exige mudanças da cultura da organização. Não é apenas criar políticas e processos. A medida do sucesso da introdução de responsabilidade social, econômica e ambiental, a empresa muda sua forma de atuar, de tomar decisões e, por definição, a sua contribuição e a sua relação com o mercado e a sociedade em que atua.

Nesse contexto, o objetivo deste artigo é descrever os benefícios de colocar a sustentabilidade no cerne da Governança Corporativa. A metodologia adotada é de abordagem qualitativa, baseada em duas vias paralelas que se complementam: por um lado, realiza-se uma pesquisa bibliográfica com a finalidade de buscar conceitos e estabelecer uma estrutura teórica que sustente a análise; por outro, é feito uma pesquisa empírica na empresa Masisa para analisar a implementação Triple Bottom Line como estratégia empresarial em dois países que a empresa atua, Brasil e Chile.

\section{A GOVERNANÇA CORPORATIVA E A SUSTENTABILIDADE}

Andrade e Rossetti (2006) apresentam quatro classificações de definições: Governança Corporativa (GC) como sistema de relação entre a direção das empresas, seus conselhos de administração, acionistas e as partes interessadas; GC que trata do conjunto de leis e regulamentações; GC como estrutura de poder, que diz respeito aos mecanismos pelos quais as corporações são dirigidas e controladas; GC como sistema normativo, a qual se refere à padrões de compor- 
tamento que conduzem à eficiência, ao crescimento dos negócios e ao tratamento a acionistas.

Por sua parte, Coimbra (2011) descreve, na sua pesquisa, as quatro dimensões conceituais distintas sobre GC: i) Conjunto de direitos e sistemas de relações - o ponto de partida dessa abordagem é o conflito de agência, decorrente da separação entre propriedade e gestão; ii) Sistema de governo e estrutura de poder - a governança estabelece as atribuições, as atividades e os poderes de decisão dos órgãos internos; iii) Sistema de valores e padrões de comportamento; iv) Sistemas normativos - consistem no conjunto de leis e normas, tanto internas como externas, além da atuação dos órgãos reguladores.

Para os objetivos deste trabalho consideramos a GC como sistema de valores e padrões de comportamento, segundo o qual as empresas têm responsabilidade tanto quanto aos seus objetivos de negócios como em relação aos interesses dos diversos stakeholders. A GC como sistema de valores e padrões de comportamento, segundo o Instituto Brasileiro de Governança Corporativa (IBGC) remete aos quatro princípios ou valores fundamentais: transparência, equidade, prestação de contas e responsabilidade corporativa entendida como a incorporação de considerações sociais e ambientais na definição dos negócios e operações (IBGC, 2009).

A Organização para Cooperação Econômica e Desenvolvimento (Organisation for Economic Co-operation and Development, pela sua sigla no inglês, $\mathrm{OECD}$ ), tem trabalhado no sentido de promover práticas de GC em todo o mundo, no ano de 1999, divulgou uma lista de princípios básicos The OECD Principles of Corporate Governance. Os Princípios de Governança Corporativa da OECD se tornaram referencias internacionais e hoje são utilizados ativamente pelos governos, órgãos reguladores, investidores, empresas e stakeholders, tanto nos paises membros quanto nos países não membros da OECD. As recomendações expostas nos princípios da OECD podem ser adaptadas às características especificas de cada país e região (KITAGAWA, 2007). Na América Latina, são quatro países que adotaram esses princípios: Argentina, Brasil, Chile e México.

No Brasil, as principais iniciativas dirigidas à GC são os incentivos oferecidos pelo IBGC. O Banco Nacional de Desenvolvimento Econômico e Social (BNDES) tem programas que valorizam a adoção de boas práticas de GC como requisito preferencial para a concessão de créditos. Os incentivos criados pela Bolsa de Valores de São Paulo (BOVESPA,) que deram origem ao Novo Mercado ${ }^{4}$ e aos Níveis Diferenciados de GC (Nível 1 e Nível 2), os quais são segmentos de listagem, voltados às companhias que adotam boas práticas de GC.

No ano de 2005, a BM\&FBOVESPA lançou o Índice de Sustentabilidade Empresarial (ISE) com o objetivo de criar um ambiente compatível com as demandas de desenvolvimento sustentável e estimular a responsabilidade socioambiental das empresas. Para avaliar a performance das empresas listadas na BOVESPA com relação aos aspectos de sustentabilidade, parte-se do conceito do triple bottom line, que envolve a avaliação de elementos ambientais, sociais e econômico-financeiros de forma integrada.

No Chile, o quadro jurídico para a governança corporativa está na Lei de Opas (19.705), Ley de Oferta pública de Adquisición de Acciones y Gobierno Corporativo, do ano 2000, que deu início a uma nova regulação financeira, e conta com altos padrões de governo corporativo para recuperar a confiança dos investidores e potenciar o desenvolvimento do mercado de capitais, além de fechar casos controvertidos, como o caso "Chispas" 5.

A Governança e a Sustentabilidade Corporativa são termos que ganham cada vez notoriedade, num mundo em que as expectativas da sociedade com relação à adoção de boas práticas pelas empresas são crescentes, após a publicação, em 1987, do relatório Brundtland que sentou

${ }^{4} \mathrm{O}$ Novo Mercado é um segmento especial de listagem de ações de companhias que se comprometem voluntariamente a adotar tais práticas, e os Níveis 1 e 2 são estágios intermediários, que, juntos com o Novo Mercado, estabelecem compromissos crescentes de adoção de melhores práticas de governança corporativa.

${ }^{5}$ Para mais informação sobre o caso "chispas", ver: Clarke (2009). 
as bases para a conhecida definição de desenvolvimento sustentável. Em 1992, a Declaração do Rio sobre Meio Ambiente e Desenvolvimento lançou a noção de três pilares do desenvolvimento sustentável, social, ambiental e econômico. Contudo, para sensibilizar as empresas, o termo usado deveria expressar uma linguagem dos negócios. Em 1994 foi criado o termo triple bottom line, segundo o qual, as corporações são focadas no seu valor econômico, ambiental e social.

Neste mesmo lineamento, o Global Compact ou Pacto Global da Organização das Nações Unidas - ONU, lançado em julho de 2000, visa a promover os valores universais, como justiça, sustentabilidade ambiental e direitos humanos. A criação do Global Compact considerou que as empresas são protagonistas fundamentais no desenvolvimento das nações e devem agir com responsabilidade na sociedade com a qual interagem.

Para Núñez (2006), os princípios do Global Compact abarcam entre outros aspectos os relacionados com a proteção e a melhoria do meio ambiente e o crescimento econômico, através da adoção de uma abordagem preventiva, tomando medidas para promover a responsabilidade ambiental e incentivar o desenvolvimento e disseminação de tecnologias limpas, incluindo sistemas de gestão, de autorregulação, o diálogo com os stakeholders, a eco-eficiência e a produção limpa.

Numa economia global, e com a internacionalização dos investimentos, as práticas de boa governança e sustentabilidade corporativa cada vez mais abarcam questões éticas, sociais e ambientais e adquirem particular relevância, especialmente no acesso ao financiamento nacional e internacional e na estabilidade deste, bem na atração de capital estrangeiro (OECD, 1999 apud NúÑEZ, 2006).

Nesse sentido, os mecanismos de governança corporativa são fundamentais para que esse processo se consolide na prática. Balancear resultados econômicos, sociais e ambientais envolve o enfrentamento de dilemas e a tomada de decisão no longo e curto prazo. Para isso, é importante que a empresa crie uma estrutura de governança para a sustentabilidade, que deve abranger os diversos níveis organizacionais (BM\&FBOVESPA, 2010).

O relatório de sustentabilidade é a principal ferramenta de comunicação do desempenho social, ambiental e econômico das empresas. O modelo de relatório da Global Reporting Initiative (GRI) é atualmente o mais completo e mundialmente difundido e tem como objetivo medir e certificar as empresas com parâmetros que vão além da questão da transparência e da boa governança corporativa. O GRI inclui os indicadores econômico, ambiental, social/ trabalho, direitos humanos, sociedade, e responsabilidade pelo produto.

\section{A SUSTENTABILIDADE COMO FERRAMENTA ESTRATÉ- GICA EMPRESARIAL}

A sustentabilidade corporativa ganha cada vez mais status de vantagem competitiva (BM\&FBOVESPA, 2010), hoje a sustentabilidade nos negócios é encarada não como uma iniciativa ambiental, e sim como uma estratégia empresarial que gera valor a partir da busca de melhores resultados sociais e ambientais. As empresas estão procurando inserir o tripé da sustentabilidade na estratégia e gestão de seus negócios, surgem novos modelos de negócios que visam ao equilíbrio entre o capital natural e o humano como desenvolvimento inclusivo com tecnologias limpas (BM\&FBOVESPA, 2010).

Surge um novo conceito de empresa orientada para práticas de sustentabilidade, cuja principal característica é o esforço para reduzir os impactos sociais e ambientais, através de adaptação de seus produtos, processos e estruturas organizacionais, tendo em conta as atitudes dos diferentes atores para realizar negócios por meio de atividades que respeitem o meio ambiente 


\section{(SCHALTEGGER et al., 2003).}

Quanto a isso, Elkington (1999) observa que o momento atual de revolução cultural exige que as empresas estejam preparadas para se dirigirem na direção do desenvolvimento sustentável. Manzini e Vezzoli (2002) afirmam que a humanidade está passando por um período de descontinuidade sistêmica, caracterizada pela tensão entre a globalização econômica, cultural, e a emergência dos limites ambientais, exigindo a transição para uma sociedade sustentável.

A sustentabilidade tem emergido como um modelo de interpretação pelas empresas, em suas três dimensões do desenvolvimento sustentável: econômica, ambiental e social. O conceito do que virá a ser conhecido como "Triple Bottom Line", cunhado por Elkington e difundida com a publicação de seu livro no ano de 1997 "Cannibals with forks: the triple bottom line of 21st century business", o qual representou a expansão do modelo de negócios tradicional - que só considerava fatores econômicos na avaliação de uma empresa - para um novo modelo, que passa a considerar a performance ambiental e social da companhia além da financeira (ELKINGTON, 1997), a combinação desses três pilares dará como resultado o que Savitz e Weber chamam de "ponto doce da sustentabilidade" (SAVITZ; WEBER, 2006).

$O$ termo mais usado para descrever o papel das empresas com o desenvolvimento sustentável é "sustentabilidade empresarial" (BM\&F BOVESPA, 2010). O princípio da sustentabilidade nas empresas, como observado por Porter e Kramer (2006), aparece frequentemente invocando o triple bottom line, que consiste na busca da continuidade no mercado e no crescimento da organização a partir de sua viabilidade econômica, além da coexistência harmônica com o meio ambiente e sociedade. A sustentabilidade se converte em um princípio fundamental da gestão inteligente, que será difícil de ser ignorado (SAVITZ; WEBER, 2006).

A responsabilidade social e ambiental assume características descritas por Buchholz (1992) como uma questão estratégica para os negócios de uma empresa, a saber:

a) coloca uma tendência ou oportunidade atual ou prospectiva; b) surge de alguma tendência ou desenvolvimento interno ou externo; c) pode ter um impacto potencial importante no crescimento, na rentabilidade ou na sobrevivência dos negócios; d) o impacto da questão pode, de alguma forma, ser influenciados pela ação da empresa. (BUCHHOLZ,1992 apud SANCHES, 2000 p.78).

Nesse novo contexto, segundo o estudo da Confederação Nacional da Indústria (CNI, 2011), o bom desempenho da empresa não se associa à sua capacidade produtiva, de inovação e de participação no mercado. Elementos de sucesso, como diferencial de preço, qualidade e fidelidade à marca, podem ser impactados pelo não engajamento no tema de sustentabilidade corporativa.

Para construir vantagem competitiva a partir de espaços não tradicionais, como do meio ambiente, Reinhardt (2000) sugere cinco passos estratégicos:

1. Desenvolvimento de novos produtos ou serviços que resolva os problemas ambientais e sociais ou que melhorem os impactos ambientais dos produtos ou serviços que substituem. 2. Novos segmentos de clientes, que privilegiam os aspectos valorizados de sua compra. 3. Diferenciação por custos mais baixos. 4. Diferenciação por aplicação da lei que seus concorrentes não podem oferecer. 5. Gestão de risco adequada (REINHARDT, 2000 apud CORREA, et al, 2010.p.26).

Competir pelo menor preço já foi a estratégia adotada pelas empresas. No entanto, com as mudanças em sentido global, além dos fatores econômicos, estruturais, climáticos, outros começam a fazer parte da responsabilidade das empresas, que são as questões do meio ambiente. A estratégia baseada na eficiência operacional não assegura mais, por si só, vantagens sustentáveis por 
longo tempo (CORAL, 2002). A proteção ambiental passa a fazer parte dos objetivos de negócios, e o meio ambiente não é mais encarado como um adicional de custo, mas como uma possibilidade de lucro, em um quadro de ameaças e oportunidades para a empresa (SANCHES, 2000).

Portanto, dentre os principais fatores condicionantes da necessidade de engajamento das empresas em relação à nova economia, destacam-se a continuidade de sua própria existência no mercado nacional e internacional, a obtenção de vantagem competitiva frente a seus concorrentes e a melhoria de sua imagem, estes podem ser alcançados se a empresa atuar como uma organização que respeita o meio ambiente (CNI, 2011).

Assim, uma empresa que adota uma responsabilidade ambiental por processos e produtos, a qual envolve um relacionamento diferente, compartilhado com fornecedores e consumidores no que se refere à prevenção da poluição, à minimização dos resíduos e à proteção dos recursos naturais, também adota uma postura na função da administração (SANCHES, 2000). Esta função da administração voltada para a sustentabilidade precisa estar contemplada na estrutura organizacional, interferindo no planejamento estratégico e passar a ser uma atividade importante na organização da empresa, gerando políticas, metas e planos de ação (DONARIRE, 1994).

Nas atividades de planejamento estratégico, a função da administração será avaliar o ambiente externo, procurando identificar, no que diz respeito às questões ecológicas, as oportunidades e os riscos existentes na legislação ambiental, no nível de consciência dos consumidores e da sociedade como um todo, no que está sendo feito pela indústria a que a empresa pertence, no comportamento dos concorrentes e no avanço tecnológico nesse campo (DONAIRE, 1999 apud CORRAZA, 2003). Para gerar valor a partir de considerações sociais e ambientais, é preciso melhorar a sua visão e estratégia, os seus processos internos, a sua cultura, e melhorar relações com seus stakeholders - colaboradores, clientes, fornecedores, comunidades, ONGs e autoridades (CORREA, et al. 2010). Integrar a responsabilidade ambiental à estratégia geral da empresa demonstra a prontidão para tornar as questões ambientais uma parte integrante da estratégia empresarial que gerará valor para a empresa.

Segundo Zadek (2004), as empresas tratam os assuntos sociais e ambientais de forma diferente, de acordo à etapa em que se encontram, conforme é descrito no Quadro1, o qual resume as cinco etapas na curva de aprendizagem, no processo da mudança organizacional para a sustentabilidade. Para Savitz e Weber (2006), a sustentabilidade promove a lucratividade para a grande maioria das empresas e traça o curso para o sucesso duradouro. Para os autores, existem três maneiras de a sustentabilidade melhorar a empresa, ajudando a protegê-la, a gerenciá-la, e a promover seu crescimento. A sustentabilidade é como um guia de orientação para fazer negócios num mundo interdependente, indicando novas maneiras de proteger a empresa contra riscos ambientais, financeiros e sociais, de dirigir a empresa com maior eficiência e produtividade, e de promover seu crescimento por meio do desenvolvimento de novos produtos e serviços e da abertura de novos mercados. 
Quadro 1 - Etapas na curva de aprendizagem da estratégia de responsabilidade corporativa

\begin{tabular}{|c|c|c|}
\hline Etapa & O que fazem as empresas? & Porque fazem? \\
\hline Defensiva & $\begin{array}{l}\text { Desconhecem responsabilidades e não } \\
\text { têm práticas ruins. }\end{array}$ & $\begin{array}{l}\text { Defender contra ataques à reputação que } \\
\text { possam afetar os resultados em curto prazo. }\end{array}$ \\
\hline Conformidade & $\begin{array}{l}\text { Adotam políticas e medidas que per- } \\
\text { mitam cumprir com normas vigentes. } \\
\text { Investimentos são considerados custos } \\
\text { necessários para operar. }\end{array}$ & $\begin{array}{l}\text { Controlar riscos para não perder valor eco- } \\
\text { nômico no médio prazo. }\end{array}$ \\
\hline Gestão & $\begin{array}{l}\text { Inclui elementos de responsabilidade } \\
\text { nos processos e sistemas de gestão. }\end{array}$ & $\begin{array}{l}\text { Controlar riscos para não perder valor eco- } \\
\text { nômico no médio prazo, aproveitando as } \\
\text { oportunidades em longo prazo. }\end{array}$ \\
\hline Estratégica & $\begin{array}{l}\text { Integra variáveis sociais/ambientais } \\
\text { dentro do core das estratégias do ne- } \\
\text { gócio. }\end{array}$ & $\begin{array}{l}\text { Apontar a geração de valor econômico no } \\
\text { longo prazo, gerar vantagem de liderança e } \\
\text { impulsionar inovação do negócio. }\end{array}$ \\
\hline Integrativa & $\begin{array}{l}\text { Promover mudanças na sociedade, } \\
\text { além do controle direto da empresa. }\end{array}$ & $\begin{array}{l}\text { Visar à geração de valor econômico no } \\
\text { longo prazo, mudar regras e gerar lucros } \\
\text { através de ações coletivas. }\end{array}$ \\
\hline
\end{tabular}

Fonte: Zadek (2004); Correa (et al. 2010).

Para Mcintosh et al. (2001), a cidadania corporativa responsável é uma questão estratégica e pode permitir às empresas obterem vantagem do novo clima de negócios, no qual os recursos naturais se tornam cada vez mais escassos, as mudanças climáticas globais ameaçam os mecanismos de suporte à vida humana e à atividade econômica, e as empresas se veem obrigadas a reagir a mudanças sociais, econômicas e ambientais.

Savitz e Weber (2006) destacam que o aquecimento global está alterando o panorama comercial e regulatório das empresas, e elas estão reagindo a esses desafios. Por exemplo, a Toyota desenvolveu um motor híbrido gasolina-electricidade. A DuPont se afasta de produtos químicos para se transformar no maior produtor mundial de proteína de soja. A Procter\&Gamble compete com a Unilever para desenvolver e vender produtos aos muitos pobres. A PepsiCo relata aumento anual de US\$ 250 milhões na receita de vendas, por aplicar programas de compras que dão preferência a fornecedores sob controle societário de mulheres e grupos minoritários. A 3M reporta economias superiores a US\$ 1 bilhão com seu programa Pollution Prevention Pays (Vale a pena evitar a poluição). Para esses autores, também, a questão das mudanças climáticas representa grandes oportunidades de negócios, e já existem empresas colhendo o fruto do ponto doce da sustentabilidade. Para a General Electric (GE), o negócio de energia eólica já quadruplicou sua receita desde que foi adquirido da Enron, em 2002. Seus motores para aeronaves e locomotivas, com maior eficiência energética, e suas turbinas a gás natural, menos poluidora, tornam-se cada vez mais essenciais para seus clientes, que buscam maneiras de reduzir suas emissões de gases de efeito estufa. GE vendeu mais de US\$1 bilhão em turbinas a vento e a gás natural para China (SAVITZ; WEBER, 2006).

O investimento no meio ambiente pode reduzir custos de produção, evitar desperdícios e ineficiência no consumo de energia e matérias primas, melhorar a imagem da empresa e de seus produtos frente ao consumidor, ou seja, revertem-se os custos em benefícios (PORTER e VAN DER LINDE,1995). No Quadro 2, observam-se os benefícios que as empresas podem conseguir pela incorporação da sustentabilidade nos negócios, o que vai desde a identificação de novas oportunidades de negócio até a detenção de um bom capital humano, atingindo menos exposi- 
ção a riscos, com base na prevenção e avaliação de riscos para as dimensões social e ambiental que the ajudaram definir as ações e estratégias para seu controle.

Quadro 2 - Benefícios que geram a incorporação da sustentabilidade.

\section{Benefícios que geram a incorporação da sustentabilidade à estratégia de negócio.}

Identificação de novas oportunidades de negócio.

Antecipação a pressões legais e da sociedade.

Redução dos custos de produção, decorrente da diminuição de desperdícios e economia de insumos.

Maior atração e retenção de talentos.

Facilidade no acesso ao capital.

Menor exposição a riscos.

Impacto positivo na reputação (ativos intangíveis).

Fidelização de consumidores.

Melhor alinhamento interno com relação a práticas e políticas adotadas.

Fonte: BM\&FBOVESPA (2010).

\section{A GOVERNANCA CORPORATIVA E A SUSTENTABILIDADE: A APLICAÇÃO DO TRIPLE BOTTOM LINE NA MASISA}

Masisa é uma empresa de origem Chilena, constituída em 1960. Sua principal linha de negocio é a produção e comercialização de painéis de madeira para móveis e arquitetura de interiores. Atualmente, a empresa tem presença em dez países latino-americanos, tem doze complexos industriais, 225.000 hectares de florestas certificadas pelo FSC (Forest Stewardship Council) e mais de 310 lojas Placacentro - pontos estratégicos de venda ao cliente final na região.

Masisa foi a primeira empresa chilena que formalizou as suas práticas de governança e transparência através de seu Código de Governança Corporativa. Esse documento reúne as recomendações de Princípios de Governança Corporativa da Organização para Cooperação e Desenvolvimento Econômico (OECD), que são instrumentos que contêm normas não vinculativas e boas práticas, bem como linhas orientadoras sobre sua aplicação.

Os responsáveis pela aplicação do modelo de Governança Corporativa da Masisa são o Conselho de Acionistas, que tem como missão definir os alinhamentos estratégicos e de governabilidade; os Comitês de assistência ao Conselho, órgãos formados por diretores que monitoram de forma contínua a aplicação da estratégia de governabilidade, a gestão de risco e a correta emissão dos balanços financeiros da Companhia; a Administração, que tem como missão gerenciar e assegurar o cumprimento de todos os elementos que formam o Modelo de Governança Corporativa; e os colaboradores, que trabalham a partir dos princípios e valores que norteiam a Masisa.

A Governabilidade em Desenvolvimento Sustentável e o amadurecimento dos temas de sustentabilidade na Masisa têm permitido delegar parte da responsabilidade aos diferentes níveis da organização. Masisa tem definido uma estrutura organizacional para contribuir com o desenvolvimento sustentável: Conselho de Administração; Diretor Geral; Diretor do País - com responsabilidade pela implementação e pelo acompanhamento das questões da sustentabilidade; Conselho para o Desenvolvimento Sustentável, como um corpo de definição estratégica; Gerência do Meio Ambiente, de Responsabilidade Social Empresarial; coordenadores de impactos ambientais e sociais diretamente responsáveis pela gestão e aplicação de medidas nas atividades da empresa. 
A Estratégia de Triplo Resultado é uma estratégia que serve de base à política de gestão de negócios da Masisa, contempla, de forma integral e simultânea, a obtenção dos mais altos índices de desempenho nos âmbitos financeiro, social e ambiental. Ela se desdobra na busca de que as ações nas áreas social e ambiental apoiem a sustentabilidade da Empresa. As ações que a empresa está realizando são descritas focando os critérios de desenvolvimento sustentável, no Quadro 3.

Quadro 3 - As ações voltadas para o Desenvolvimento Sustentável (DS) da Masisa no Brasil e Chile

\begin{tabular}{|c|c|}
\hline \begin{tabular}{|l} 
Critérios C \\
DS \\
\end{tabular} & stacadas. \\
\hline Social & $\begin{array}{l}\text { Negócios Inclusivos - Masisa tem o programa de relacionamento direto com pequenos e } \\
\text { médios marceneiros, executado em conjunto com a rede Placacentro. } \\
\text { Gestão de Capital Humano - Através da cultura de confiança, aplica meritocracia, serviço } \\
\text { ao cliente e inovação. } \\
\text { Gestão de Saúde e Segurança - Índice de Frequência de Acidentes de Trabalho, Índice de } \\
\text { Severidade dos Acidentes de Trabalho. } \\
\text { - Durante } 2011 \text {, foram investidas } 126.000 \text { horas em treinamento de Segurança e Saúde } \\
\text { Ocupacional, para colaboradores diretos e indiretos, com o objetivo de diminuir o } \\
\text { indice de acidentes. } \\
\text { Desenvolvimento de talentos através das seguintes ações: } \\
\text { - Introdução da avaliação } 360^{\circ} \text {; } \\
\text { - Desenvolvimento das competências comerciais; } \\
\text { - Workshops de liderança; } \\
\text { - Programas de coaching; } \\
\text { - Programa de rotações temporárias; } \\
\text { - Incentivo de equipes de trabalho remoto; } \\
\text { - Desenvolvimento de facilitadores internos no programa Marca de Liderança. } \\
\text { Educação e desenvolvimento - Em } 2011, \text { o investimento realizado em capacitação, no } \\
\text { nível regional, foi de US\$ } 1.989 .654, \text { e o total de horas de formação, no ano, pelo total de } \\
\text { empregados, foi de } 313.601 \text { horas. } \\
\text { Relacionamento com o público de interesse - relacionamento com os municípios vizinhos. } \\
\text { - Plano Colaborativo frente às necessidades locais: apoio ao plano municipal de susten- } \\
\text { tabilidade e geração de empregos, capacitando mulheres para o empreendedorismo } \\
\text { no Chile. } \\
\text { Educação: } \\
\text { - Projeto “Vamos ler, preservar e reciclar”, iniciativa para trabalhar no processo de } \\
\text { reciclagem dos jornais, com } 350 \text { pessoas, incluindo estudantes, professores e autori- } \\
\text { dades locais, no Brasil } \\
\text { Programa de educação ambiental, com } 17 \text { escolas rurais. Para } 1274 \text { alunos, } 28 \text { profes- } \\
\text { sores, } 60 \text { responsáveis, } 2 \text { Escolas técnico-profissionalizantes, Universidade do traba- } \\
\text { Ihador - Infocap, } 40 \text { novos marceneiros formados em linha plana no Chile. }\end{array}$ \\
\hline
\end{tabular}




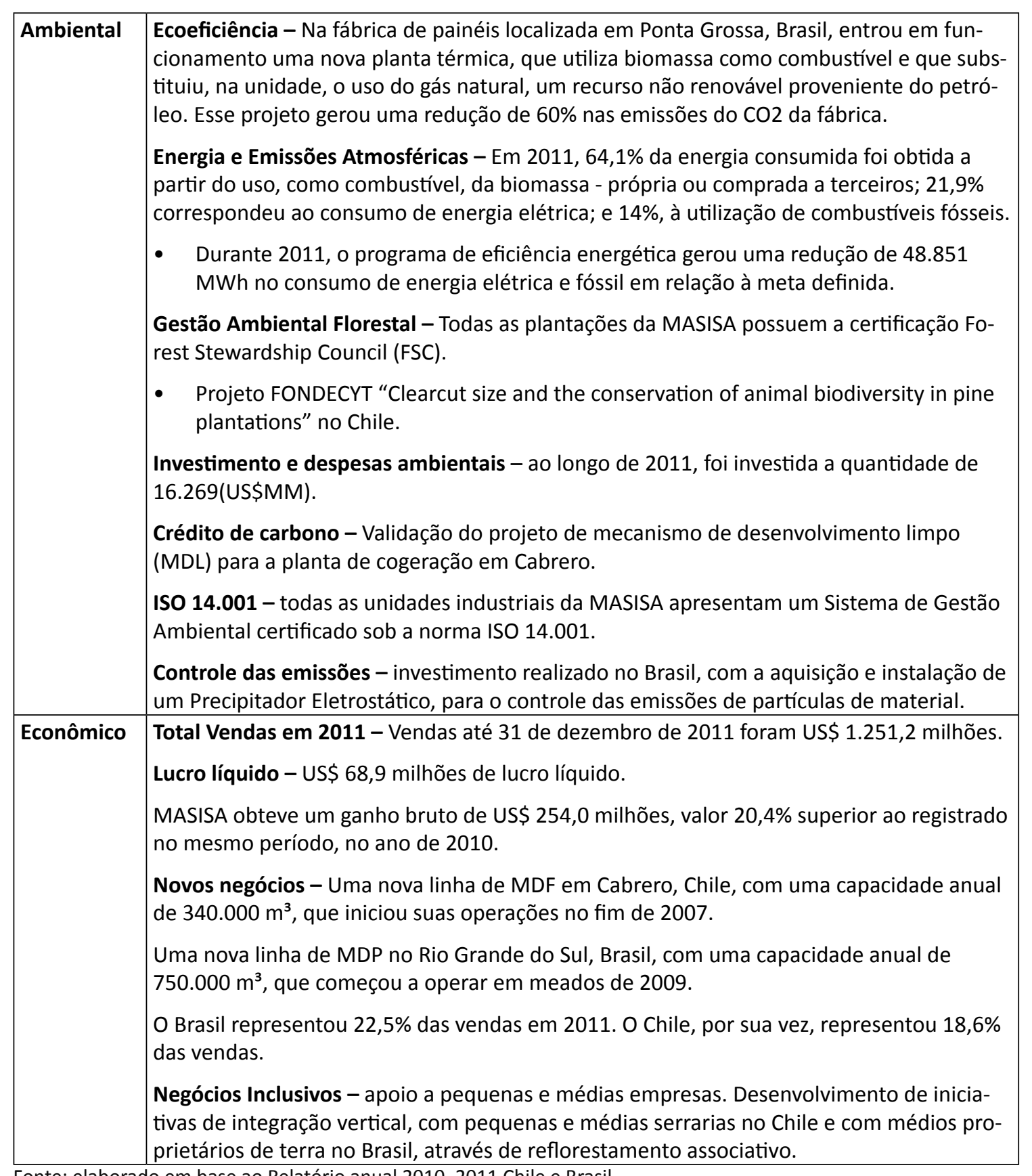
Fonte: elaborado em base ao Relatório anual 2010, 2011 Chile e Brasil.

Nas palavras do Presidente da Masisa, plasmada no relatório anual 2011, apesar de o ano de 2011 ter sido marcado por incertezas mundiais e pela ameaça permanente de uma nova crise financeira, a Masisa conseguiu se posicionar, implementando sua estratégia competitiva, a Estratégia de triplo resultado. Dentre os benefícios, por ser uma empresa preocupada com a sustentabilidade, pode-se mencionar os reconhecimentos alcançados durante os anos 2010 e 2011.

No Brasil, no ano de 2010, a Masisa foi apontada como uma das vinte empresas modelo em sustentabilidade no País. Foi o terceiro ano consecutivo em que a Masisa figurou entre as empresas eleitas pelo Guia Exame de Sustentabilidade, a partir de uma pesquisa realizada anualmente pela revista da Editora Abril, abordando aspectos de governança corporativa e desempe- 
nho econômico, ambiental e social.

No mês de julho de 2010, o Portal da Revista Imprensa divulgou o ranking "As 100 empresas mais sustentáveis segundo a mídia". A Masisa ocupou a 5a posição na categoria que reúne as indústrias de material de construção e a 154 a posição geral, ficando entre as $25 \%$ melhor posicionadas no universo das 600 empresas avaliadas. Em 2011, a Masisa recebeu do Governo do Chile o selo de distinção pelo seu compromisso com a superação da pobreza. A empresa recebeu um selo de reconhecimento pelo seu programa de oportunidades de negócios inclusivos para marceneiros que fabricam mobiliário para moradias de interesse social, contribuindo para a superação da pobreza.

Entre outros reconhecimentos, em 2011, "Novo Campeão de Sustentabilidade", no Fórum Econômico Mundial, realizado em setembro, na China. Para a preparação do estudo, o Fórum Econômico Mundial e o The Boston Consulting Group (BCG) analisaram mais de 1000 empresas, identificando as 16 companhias que compartilham práticas similares e formas de conceber seus negócios a partir de uma visão responsável no manejo dos recursos do planeta.

\section{CONCLUSÕES}

Com o presente trabalho, pretendeu-se traçar um paralelo entre a importância da governança e a cidadania empresarial. As empresas precisam inovar e adaptar suas práticas de GC para se manterem competitivas num mundo em mudança, para atenderem novas demandas e novas oportunidades e para estarem em melhores condições para realizar sua função principal, de gerar riqueza e valor numa base sustentável. Assim, há uma necessidade de colocar a sustentabilidade no cerne da governança corporativa, porque empresas que apresentam governança apresentam mais oportunidades para tomar decisões que respeitem acionistas, empregados, sociedade e meio ambiente.

Nesse sentido, os mecanismos de governança corporativa são fundamentais para que esse processo se consolide na prática. Para isso, é importante que a empresa crie uma estrutura de governança para a sustentabilidade. Aliada à ação do governo, a empresa deve levar em conta a natureza dinâmica de governança corporativa e projetar um quadro legal e regulatório suficientemente flexível para permitir tal adaptabilidade.

A prática da sustentabilidade gera custos às empresas, é preciso investir em equipamentos para adequação das linhas de produção, que não causem danos ambientais excessivos em treinamentos a seus colaboradores, campanhas internas de conscientização, entre outras ações, o que, no curto prazo os ajustes são inevitáveis, mas apresenta resultados compensadores em médio e longo prazo, revertendo-se os custos em benefícios, como mencionam Porter e Van Der Linde (1995) e, ainda, sendo uma oportunidade para as empresas de se posicionarem no mercado e melhorarem sua imagem perante investidores e consumidores.

Também, a motivação central para os empresários é o desejo de melhorar o desempenho financeiro do negócio. A sustentabilidade é uma tendência que está surgindo no mundo corporativo, está no centro de seus negócios e representa uma esperança para o desenvolvimento de uma nova mentalidade na atividade empresarial, porque hoje a sustentabilidade nos negócios é encarada não como uma iniciativa ambiental, e sim como uma estratégia empresarial que gera valor a partir da busca de melhores resultados sociais e ambientais.

Pode-se observar, na empresa Masisa, que existe um esforço na integração da responsabilidade ambiental e social à governança da empresa, além da demonstração de prontidão para tornar as questões ambientais uma parte integrante da estratégia empresarial. Os benefícios de 
ser uma empresa sustentável já são percebidos, pela melhora da imagem, valorização da marca e reputação da empresa frente à sociedade. $O$ desempenho ambiental da empresa está fornecendo o reconhecimento público de exemplo e líder empresarial na área da sustentabilidade, facilitando o seu envolvimento com as partes interessadas e motivando a todos os envolvidos a seguir trabalhando no lema da sustentabilidade, embora esses esforços da empresa sejam fortes nos países com legislações mais exigentes do que nos outros onde a empresa atua. 


\section{REFERÊNCIAS}

ANDRADE, A.; ROSSETTI J. Governança corporativa: fundamentos, desenvolvimento e tendências. 2006.2ed. São paulo: Atlas.

ALVES, L. E. S. Governança e cidadania empresarial. Revista de Administração de Empresas, São Paulo, v.41, n.4, p.78-76, out/ dez.2001.

BM\&FBOVESPA. Novo Valor: Sustentabilidade nas empresas como começar, quem envolver $\mathrm{e}$ o que priorizar. São Paulo, 2010.

CLARKE, A. Buenos gobiernos corporativos para los negocios. El caso de Chile. In: NUNEZ,G. et.al. (Cord.). Gobernanza Corporativa y desarrollo de mercado de capitales en América Latina. CEPAL - Comisión Económica para América Latina y el Caribe.2009.

COIMBRA, F.C. Estrutura de governança corporativa e gestão de riscos: um estudo de casos no setor financeiro. Tese (doutorado) apresentada à Faculdade de Economia, Administração e Contabilidade da Universidade de São Paulo, 2011.

CORREA, M.; VAN HOOF, B.; NÚÑEZ, G. Cambio y oportunidad: la responsabilidad social corporativa como fuente de competitividad en pequeña y medianas empresas en América Latina y el Caribe. CEPAL - Comisión Económica para América Latina y el Caribe. Washington, D.C. 2010.

CNI - Confederação Nacional da Indústria Industria. Estratégias Corporativas de Baixo Carbono: Gestão de Riscos e Oportunidades. Brasília, 2011.

DONAIRE, D. Considerações sobre a influência da variável ambiental na empresa. Revista de Administração de Empresas, São Paulo, v34, n.2, p.68-77. Mar/Abri. 1994.

ELKINGTON, J. Cannibals with forks: the triple bottom line of 21st century business. Oxford:
Capstone. 1997.

Petroleum in the $21^{\text {st }}$ century: The triple bottom line: implications for the oil industry. Oil \& Gas, v. 97, n. 50, dez. 1999.

FERREIRA, R. N. Responsabilidade social, governança corporativa e valor das empresas. Revista de Administração da UFLA, Lavras, v.6, n.1, p.132-141, jan/jun.2004.

HILL, C.; W.L; JONES, G. R. Strategy Management Theory an integrated approach. 6ed. Boston: Houghton Mifflin Company, 2004.

INSTITUTO ETHOS. O Compromisso das Empresas com o Meio Ambiente - a Agenda Ambiental das Empresas e a Sustentabilidade da Economia Florestal. São Paulo, 2005.

KITAGAWA. C.K. Nível de adesão de empresas latino-americanas aos princípios de Governanca Corporativa recomendadas pela OECD. 2007. Dissertação (Mestrado) - Faculdade de Economia, Administração e Contabilidade de Riberao Preto da Universidade de São Paulo.

MANZINI, E.; VEZZOLI, C. O desenvolvimento de produtos sustentáveis. São Paulo: Editora da Universidade, 2002.

MCINTOSH. M.; LEIPZIGER, D.; JONES, K.; COLEMAN, G. Cidadania corporativa: estratégias bem-sucedidas para empresas responsáveis. Rio de Janeiro: Qualitymark, 2001.

MORELBA, B. Gobernanza empresarial: Ética, Responsabilidad Social y Rentabilidad en la "era Pos-Enrom". Revista Venezolana de Gerencia, 12, nro. 38, 2007, p. 183-206.

NÚÑEZ G. El Sector Empresarial en la Sostenibilidad Ambiental: Ejes de Interacción. Comisión Económica para América Latina y el Caribe (CEPAL. Santiago de Chile. 2006.

ONU - Organización de las Naciones Unidas. Objetivos del Desarrollo del Milenio: avances en la sostenibilidad ambiental del desarrollo 
en América Latina y el Caribe. Enero de 2010.

PRAHALAD, C. K.; RANGASWAMI, M.R. Why Sustainability Is Now the Key Driver of Innovation? Harvard Business Review, v. 87, n. 9, p. 27-34, set. 2009.

PORTER, M.; LINDE, C. V. Green and Competitive: Ending the Stalemate. Harvard Business Review. P.120-134, sep/oct, 1995.

PORTER, M; KRAMER, M. Strategy and Society: The Link Between Competitive Advantage and Corporate Social Responsibility. HBR Spotlight, Harvard Business Review . December 2006.

SACHS, I. Caminhos para o Desenvolvimento Sustentável. Rio de Janeiro: Garamond, 2000.

SANCHES, C. Gestão Ambiental Proativa. ERARevista de Administração de Empresas. Jan/ Mar. 2000. São Paulo, v.40, n1. p.76-87.

SAVITZ, A. W.; WEBER, K. The triple bottom line: how today's best-run companies are achieving economic, social, and environmental success - and how you can too. San Francisco: Wiley \& Sons, 2006.

SCHALTEGgER, S.; BURRITT, R.; PETERSEN, H. An introduction to corporate environmental management: striving for sustainability. Sheffield: Greenleaf, 2003.

ZADEK, S. The Path to Corporate Responsibility. Harvard Business Review. December, 2004, 82, 12, pp. 125-132. 
